des Glases, dass es nicht möglich war, denselben herauszubringen. Zur Zeit dieser Explosion war, was ich noch bemerken muss, die Thür des Schrankes offen, so dass das Licht wahrscheinlich zersetzend auf den Chlorkalk eingewirkt hat, und zwar so, dass die unterchlorige Säure in freies Chlor und Sauerstoff zersetzt worden ist, welche beide Gase durch ihre Expansivkraft die Explosion veranlasst haben.

\title{
Notiz über Salzsäuredestillation.
}

(Briefliche Mittheilung von Hrn. B. Hirsch an Dr. Bley.)

- - In Berlin, wo ich zu der häufig vorkommenden Destillation von Salzsäure niemals unter 15 Pfd. Kochsalz verwandte, habe ich niemals eine vorübergehende Fïrbung der Waschflissigkeit beobachtet; hier wiederholt schon bei weit geringeren Quantitäten. Bei den Examenarbeiten wurde häufig gefärbte Säure erhalten, doch ist eine vorübergehende Färbung der Waschflüssigkeit meiner Zeit dort nie beobachtet worden, die Färbung wurde immer auf Nachlässigkeit oder Unsauberkeit zurückgeführt. $\mathrm{Da}$ die Fürbung der Waschflüssigkeit sehr schnell vorübergeht, bin ich sehr geneigt zu glauben, dass in vielen Fällen jodhaltiges Kochsalz verwendet worden, und eine vorübergehende Färbung nicht bemerkt oder nicht beachtet worden ist. Das Kochsalz pflegten die Coursisten in dem ersten besten Materialladen zu kaufen, und sind doch wahrscheinlich verschiedene Bezugsquellen, oder auch dieselbe Fabrik mag öfter Salz von verschiedener Reinheit liefern. Brom habe ich übrigens niemals auffinden können, während es mir vor einigen Jahren gelungen ist, Brom und Jod aus Salpetersäure zu isoliren, die ich aus Rückständen von Reinigung des Natronsalpeters destillirt hatte. Die bei Rectification dieser Säure zuerst stark gefärbt übergehenden circa 6 Unzen gaben Brom und 'od in solcher Menge, dass beide isolirt dargestellt werden konnten. 